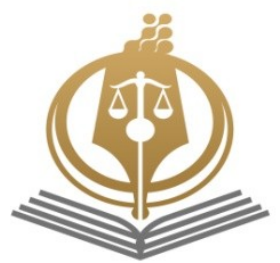

Interdisciplinary Legal Research

Apr 2020, 1(1): 31-38

Available online on: www. ilrjournal.ir

e-ISSN:2717-1795

ORIGINAL RESEARCH PAPER

\title{
Juridical and Legal Analysis for Legislative Gaps of Wisdom Dia (BloodMoney)
}

Rahmatollah Rezaei ${ }^{1 *}$ Abol-Hasaan Shakeri ${ }^{2}$

Received:

21 Mar 2020

Revised:

27 Mar 2020

Accepted:

28 Mar 2020

Available Online:

01 Apr 2020
Keywords:

Retaliation (Qisas),

Blood Money (Dia),

Psychological

Interruption,

Ath,

Insanity.
Background and Aim: Wisdom (Aql) is one of god's blessings to man. In order to maintain the health of Wisdom, the holy legislator, supports against several minor and partial injuries to wisdom (Aql) and covers the damage by complete or partial Dia (Blood money). Consequently, chapter five of the second part of the Islamic Penal Code is dedicated to the problems of wisdom (Aql).

Materials and Methods: The descriptive - analytical approach has been chosen as the method of present study.

Ethical Considerations: Honesty and confidentiality as well as authenticity of the texts have been observed.

Findings It seems that there are serious weaknesses in Iranian legislative criminal system in this regard which did not mentioned in the juridical books. One of the most important examples is the concept of "Atah". Although the word "Atah" is common in a period between insane and Madness, but it does not mean insanity. Likewise, in explaining the position of this concept among mental disorders, due to the lack of interruptions in relation with the realities of the world around him as well as loss of function, it is placed in category of nervouses. In the case of retaliation in crimes which causes decline or lack of reason (Aql), the evidence of the group which agrees with the execution of punishment (Qisas) is Sound.

Conclusion: Iranian Penal Law should be modified to cover some kinds of Wisdom injuries.

\footnotetext{
1 * Assistant Professor of Law, Payame Noor University, Tehran, Iran. (Corresponding Author) Email: Rezaei063@gmail.com Phone:+989113540139

2 Professor, Department of Criminal Law, University of Mazandaran, Babolsar, Iran.
}

Please Cite This Article As: Rezaei, R \& Shakeri, A (2020). "Juridical and Legal Analysis for Legislative Gaps of Aql Blood Money”. Interdisciplinary Legal Research, 1 (1): 31-38. 


\title{
تبيين فقهى - هزشكى خلأهاى تقنينى مربوط به ديه عقل
}

\author{
رحمت الله رضايى'، ابوالحسن شاكرى`
}

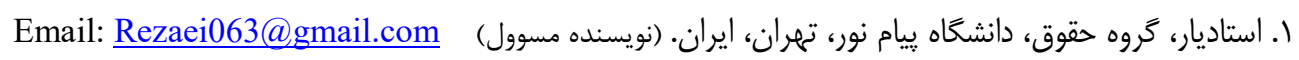
r. استاد، كروه حقوق جزاو جرمشناسى، دانشخاه مازندران، بابلسر، ايران.

دريافت:

زمينه و هدف: عقل از بزركترين نعمتهاى الهى به انسان است. شارع مقدس با علم به اين موضوع به منظور حفظ سلامت عقل، هتر حمايت خود را

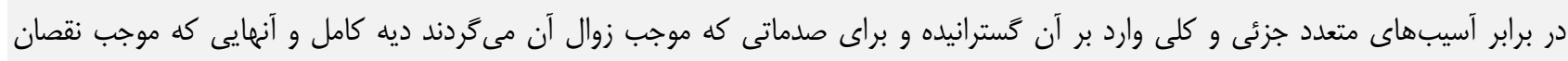

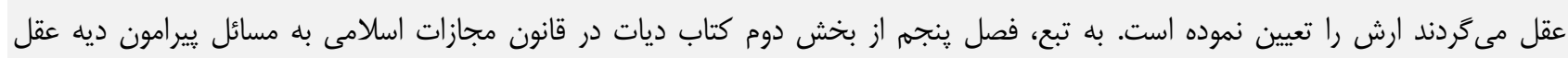
اختصاص يافته است. مواد و روشها: روش تحقيق ما در اين يثوهش، توصيفى - تحليلى است.

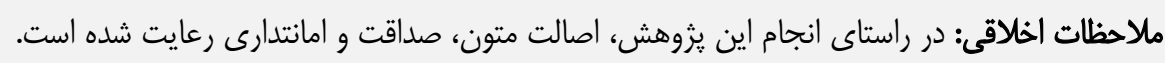

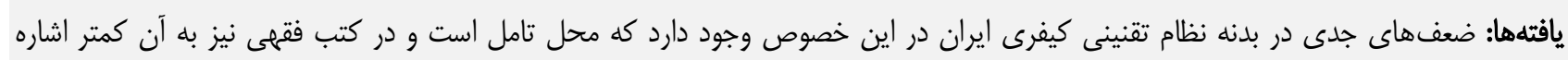

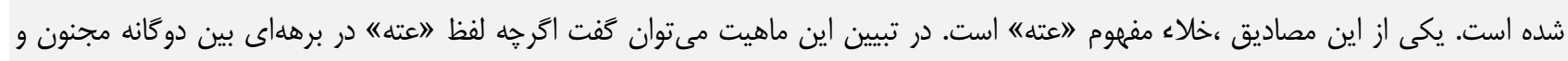

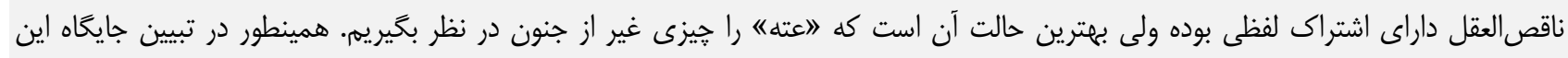

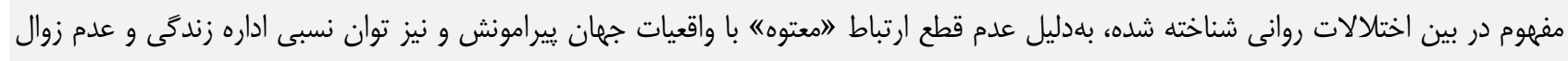

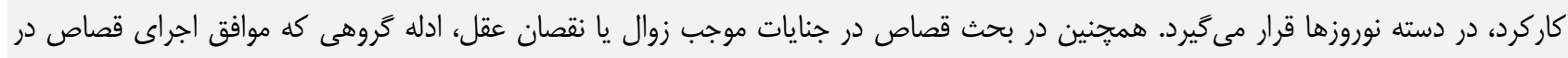

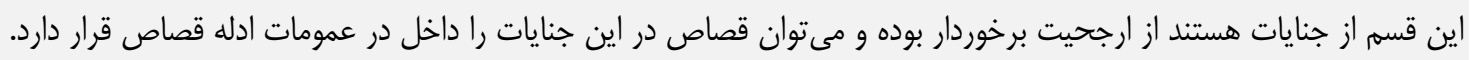

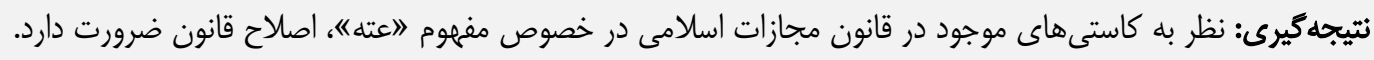
كلمات كليدى: قصاص، ديه عقل، اختلال روانى، عته، جنون. 
ترادف معنايى برقرار كردهاند. بر اين اعتقاد معتوه را مىتوان

همان مجنون و يا قسمى از آن به حساب آورد. 》عته در اصطلاح فقهى نيز اكثراً به همين دو معنا آمده است.

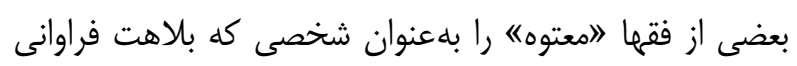

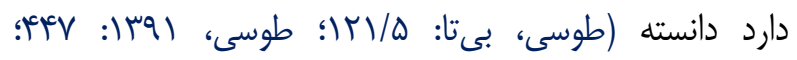

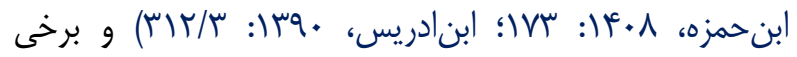
ديخر "معتوه" را بهعنوان شخصى كه عقلى ندارد تعريف كردهاند. (طباطبايى، ع.+ع|: 99) بعضى فقها نيز از لمعتوه" بلعنوان شخصى ضعيفالعقل (طريحى، ناقصالعقلى كه نه مجنون است و نه حيران و سركثته تعبير

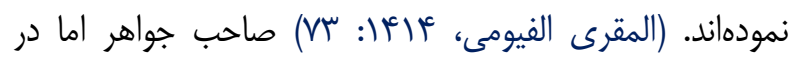
مورد 》امعتوه" تعبير ناقصالعقلى كه به مرحله جنون نرسيده

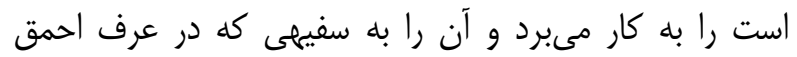
شناخته مىشود و نه سفيه شرعى تعريف مى كند. (نجفى،

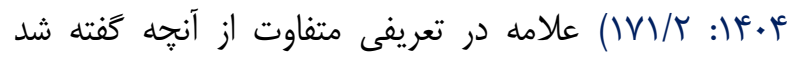
"معتوه" را شخصى مى داند كه دجار نقيصه عقلى است و رشد عقلى اش متوقف شده ليكن مجنون به حساب نمى آيد بلكه با رها توجه به ميزان رشد عقلىاش بايد مجازات شود.

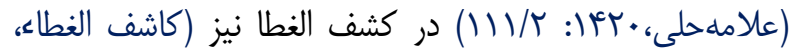
بىتا: / /عم|) در تعريفى نزديك به آنجه علامه حلى ارائه داده، 》عته/ حد وسط جنون و عقل آمده است.

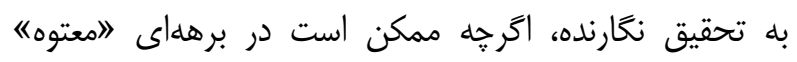
داراى اشتراك لفظى بين معانى مجنون و ناقصالعقل باشد ولى

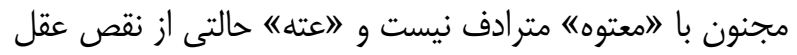
است كه به درجه جنون نرسيده است، پِ تعاريفى كه اين دو مفهوم را مترادف همديخر نشان مىدهند به نظر داراى اشكال

ץ- روش تحقيق: روش تحقيق در اين يزوهش بلصورت تحليلى و توصيفى است. بحث و نظر 1- جايكاه عته در اختلالات روانى با اين بيش فرض كه 》هعتوه" شخصى غير از مجنون است، در تطبيق 》عته) با اختلالات روانى شناخته شده ابتدا بايد كفت

\section{مقدمه}

ا- بيان موضوع: در قانون مجازات اسلامى זجسا به تأسى از فقه اماميه موضوع حمايت از سلامت عقل در برابر آسيبهاى

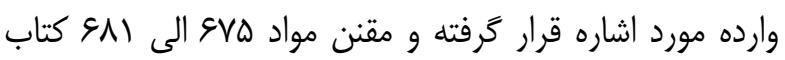
ديات اين قانون را به اين مهم اختصاص داده است. با دقت در مواد مذكور مشخص مىشود كه در اين خصوص ابهامات جدى

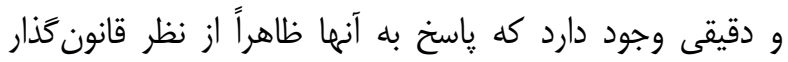
ينهان مانده و علت آن نيز مىتواند دلايلى نظير كم سابقه بودن اين موضوع در فقه و به تبع آن سكوت در كتب فقهى باشد. يكى از مصاديق بارز اين خلاء قانونى، عدم اشاره به مفهوم و حكم "عته) بهعنوان يكى از درجات نقصان عقل است. در روايات وارده از سوى اهل بيت (ع) يكى از عارضههاى روانى لهن

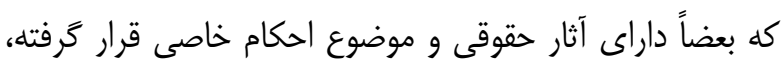
مفهوم "اعته) (به فتح عين و فتح تاءو يا به ضم عين و سكون تاء) است. اين مفهوم عليرغم ورود ديرباز به حيطه فقه به نظر مىرسد داراى مرز بندى مشخصى از ديگر مفاهيم نزديك به

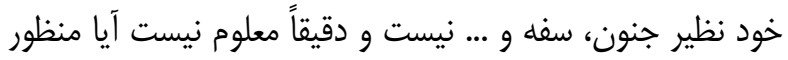

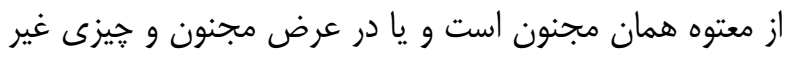

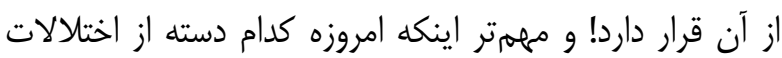
روانى قابل تطبيق با عته است و اگر بر اثر جنايت وارده كسى تردي دجار عته كَدد آيا يرداخت ارش راهكار مناسبى براى جبران خسارت وارده است يا اينكه بايد ديه كامل يرداخت شود! ارائه تعريفى درست از مفهوم "امعتوه" و يافتن راهكار مناسب براى جبران خسارت جانى در فرضى كه با ايراد جنايت، مجنى عليه دجار "اعته/ گرديده و تطبيق اين حالت با اختلالهاى روانى شناخته شده، هدف اين نوشتار است. ץ- تبيين مفهوم: "اعته| در لغت از يك سو به معناى نقص

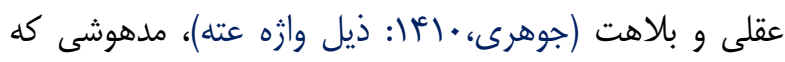
با جنون متفاوت است (فراهيدى،•أثا: ذيل وازه عته)، ضعفالعقل، سفه عرفى (شاهرودى و همكاران، وبءا: ذيل وازه عته) و نيز نقص عقلى كه نزديك به جنون است (زبيدى، ألأبا؛

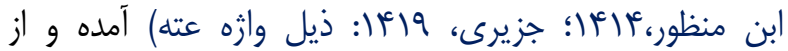
سوى ديخر برخى از علماى اهل لغت بين لاعته| و جنون 
بالايى دارد؛ همين طور خصوصيات 》معتوه" بالاى هجده سال نيز با كم توانان ذهنى دجار اختلالات يادكيرى، داراى تطابق

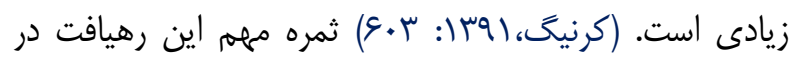
اينجا است كه به كمى آن در فرض ايراد جنابت موجب لاعته"

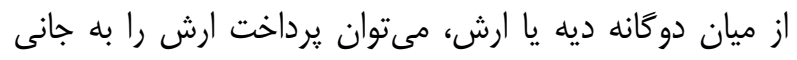
تحميل نمود هراكه اين عارضه كاركرد عقل را بهكلى زائل نكرده و موجب قطع ارتباط فرد با واقعيت جهان بيرامون خود نخواهد شد. از آنجا كه 》اعته) برخلاف جايعاه فقهى آن، در قانون مجازات اسلامى شناخته شده نيست و اين قانون فقط بلطور كلى در

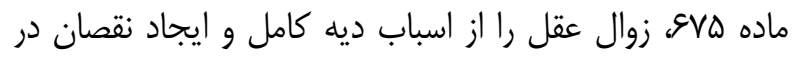
آن را از اسباب ارش دانسته است، شايسته است كه مقنن ضمن

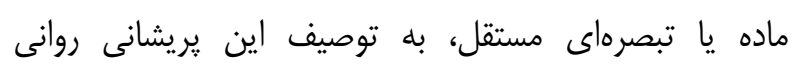

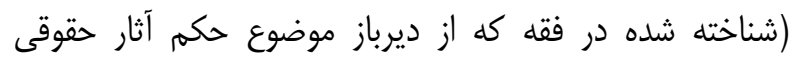

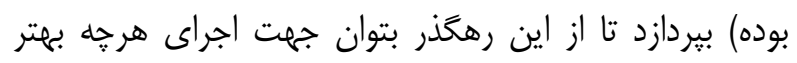
عدالت و دفع ضرر و رفع تحير محاكم قضايى كام برداشت. r- قصاص در جنايات موجب زوال يا نقصان عقل

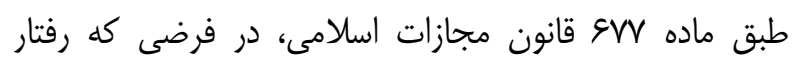
جانى (مانند ايراد ضربه و يا ايجاد وحشت) موجب نقصان عقل ماده مجنى عليه و نقصان عقل او (=عته) گَردد، امكان قصاص منتفى إنى

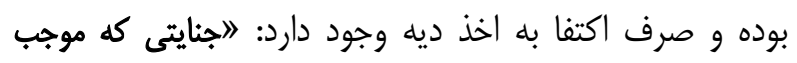
زوال عقل يا كم شدن آن شود هرجند عمدى باشد حسب مورد موجب ديه يا ارش است و مرتكب قصاص نمى لشود.《 اينكه مقنن جگَّنه به اين موضوع دست يافته كه در منفعت عقل كه جزء

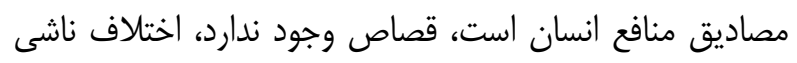
از ابهام در ارشادى يا مولوى بودن نهى شارع است. در اينجا

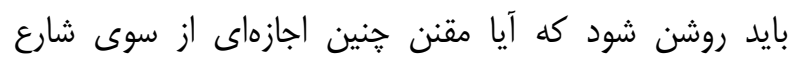

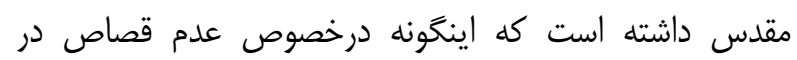
جنايات موجب زوال يا نقصان عقل و تبديل آن به ديه حتى در

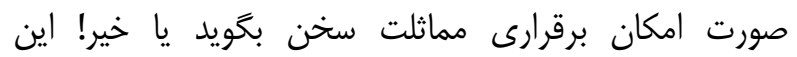
موضوع، مصداقى از موارد قصاص در منفعت است و اساساً در

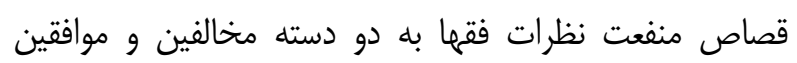

كه اختلالات روانى به دو دسته سايكوزها (روانيريشانه) و نوروزها (غير روانيريشانه) تقسيم مىشوند (ستوده و همكاران:

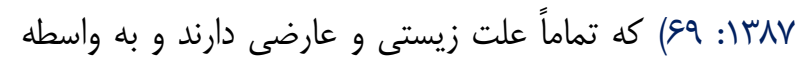
اختلال در قواى عقلانى، كاركرد عقل را زائل نموده يا كاهش داهـ

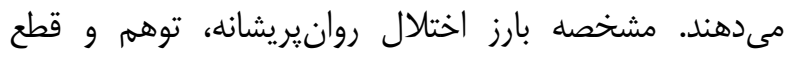

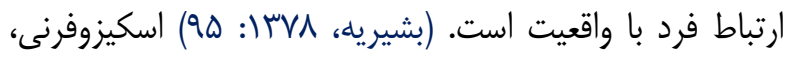
اختلال دو قطبى و اختلال شخصيت يارانوييد از اقسام اختلالات سايكوز است كه موجب اختلال شديد در كاركردهاى روانى هميّون انديشه، عاطفه، ادراك، تمركز، توجه و بصيرت

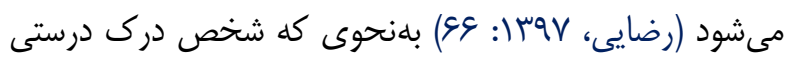
از ييرامون خود ندارد. در مقابل، اختلال روانى نوروزها (غير آنهات روانيريشانه) شامل اختلال ضد شخصيت اجتماعى، اختلال شخصيت خود شيفته، افسردگى، اختلال خواب، عقب ماندكى اختى

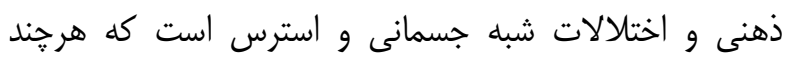
موجب قطع تماس با واقعيت نيستند ولى در تصميمَّيرى و قضاوت اشخاص نسبت به جهان يبيرامون تاثيركذار مىباشد.

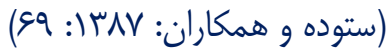
درخصوص جانمايى "اعته" در هر يك از دستههاى دوخانه

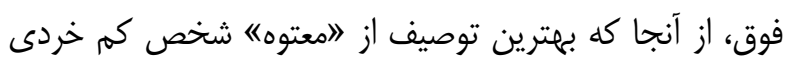
است كه با مجنون متفاوت است و مىتوان او را در زمره

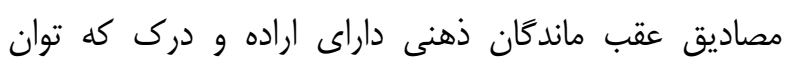

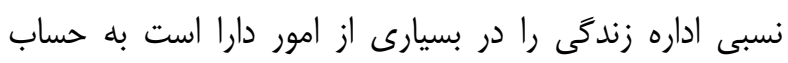

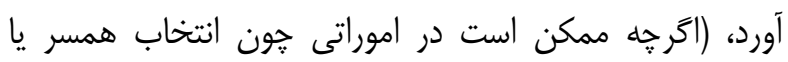
مباحث مالى نيازمند كمك باشند ولى كاركرد عقلشان زائل

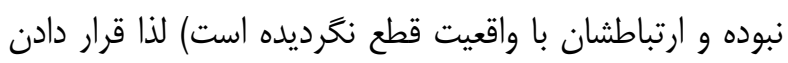
اين افراد ذيل اشخاصى داراى اختلال روانى غير روانيريشانه

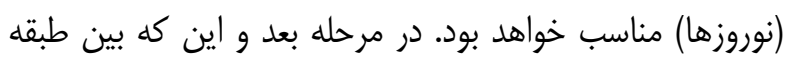

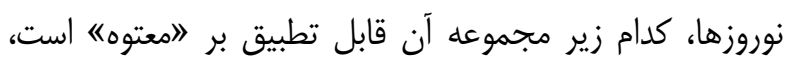

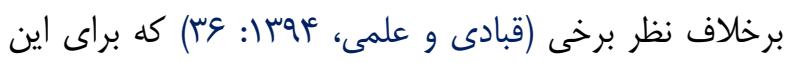
دسته از افراد، نظيرى را در اقسام اختلالات روانى قابل انطباق

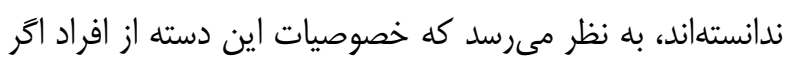
קنانجه زير هجده سال باشند با اختلالات عقب ماندكًان ذهنى

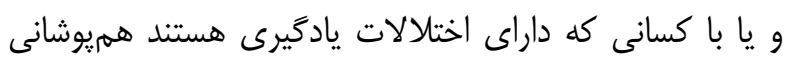


بر اثر ييشرفت علم و تكنولوزى امكان برقرارى مماثلت و رعايت تساوى وجود دارد. از سويى ديخر ادله قصاص (و بلهور

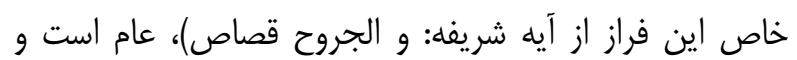
شامل نفس و هم شامل عضو و منفعت مىشود. قاعده احتياط در خون نيز ايجاب مىنمايد كه جوانب احتياط در قصاص تدارى ديده شود و فرض مساله، امكان ايجاد مماثلت و تساوى

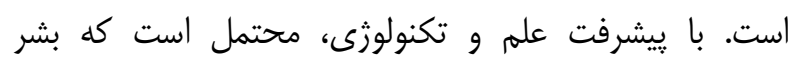

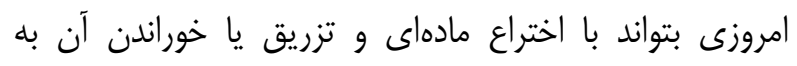
ديخرى وى را دهار صدماتى نظير زوال يا نقصان عقل نمايد. عدالت و انصاف نيز حكم مى كند كه زمانى كه قصاص در منافع جارى است در تمام فروع آن نيز جارى باشد.

\section{نتيجه}

در تبيين ماهيت 》اعته/ بهدست آمد كه اخرجه اين لفظ در

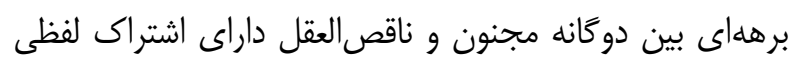

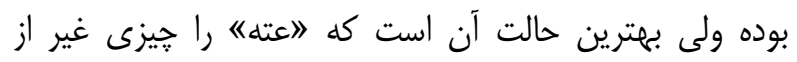
جنون در نظر بحيريم. همينطور در تبيين جايياه لاعته) در بين اختلالات روانى شناخته شده، بلدليل عدم قطع ارتباط "معتوه" با واقعيات جهان ييرامونش و نيز توان نسبى اداره زندكى و عدم زوال كاركرد، در دسته نوروزها قرار مى گيرد و از بين نوروزها

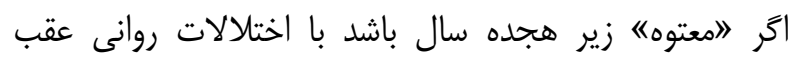
ماندكان ذهنى و كسانى كه دهار اختلالات يادكيرى هستند قابليت تطابق دارد و اكر معتوه بالاى هجده سال باشد با افرادى

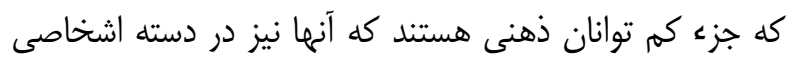
كه دجار اختلالات يادگيرى مىباشند قابليت تطبيق و هم

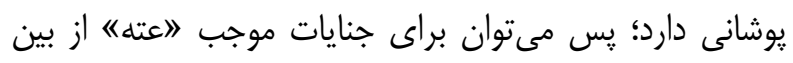

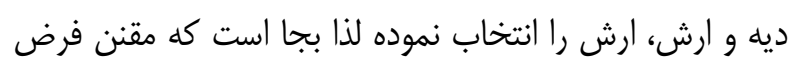

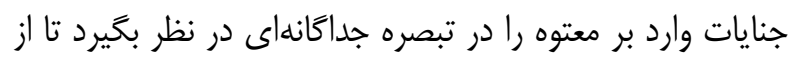
اين طريق ضعف قانون مجازات اسلامى در اين زمينه جبران و در جهت اجراى هر קه بيشتر عدالت و رفع تحير محاكم

$$
\text { قضايى كام برداشته شود. }
$$

همجنين در بحث قصاص در جنايات موجب زوال يا نقصان عقل، ادله گروهى كه موافق اجراى قصاص در اين قسم از r-1 - مخالفين اجراى قصاص

اين گروه از فقها، قصاص در جنايات موجب زوال نقصان عقل را يا به اين علت كه قصاص در جنايات وارد بر منافع كه عقل

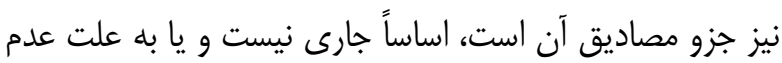
امكان مماثلت و تساوى در جنايات موجب زوال يا نقصان عقل و اينكه در اينكونه موارد احتمال سرايت به نفس و تلف جسمانى وجود دارد، مجاز نمى شمرند. البته به دلايل فوق بايد قاعده احتياط در خون را نيز اضافه نمود.

\section{r-r-موافقين اجراى قصاص}

ادله موافقين اجراى قصاص در جنايات موجب زوال يا نقصان عقل، به اختصار، بدين شرح است: (() قصاص در منافع داخل در عمومات قصاص است و آيات متعددى (مائده/ه؟؟'

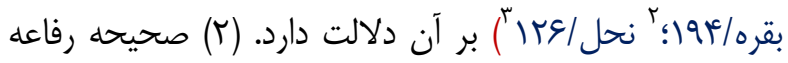

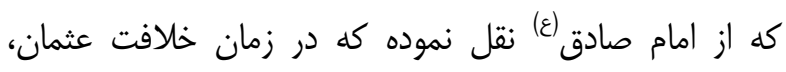
شخصى نزد خليفه براى شكايت از مردى رفت كه با سيلى

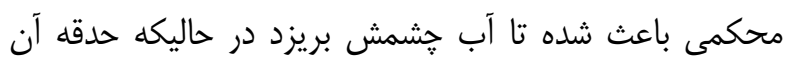

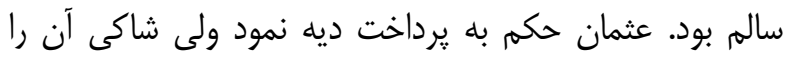

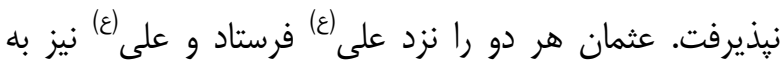

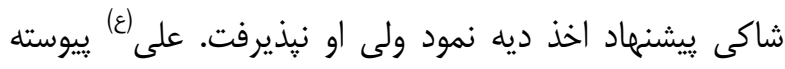

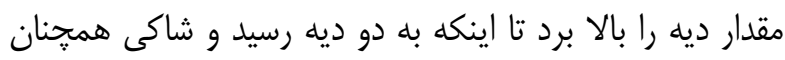
از اخذ ديه شانه خالى مى كرد و قصاص مىخواست و امام در

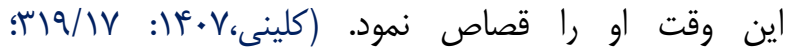

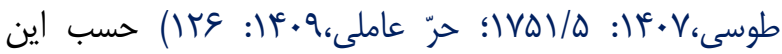

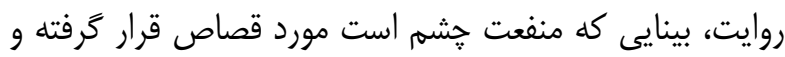
البته منفعت بينايى موضوعيت ندارد ب-r- مختار نكارنده به زعم نغارنده دلائل موافقين اجراى قصاص موجهتر است. جنانجه دليل مخالفت در اجراى قصاص در منافع عقل، ترس از عدم امكان مماثلت و رعايت تساوى باشد، فرض آن است كه

- و و كتبنا علييهم فيها ان النفس بالنفس و العين بالعين و الانف بالانف والاذن بالاذن و السن بالسن و الجروح قصاص. ' '- فمن اعتدى عليكم فاعتدوا بمثل ما اعتدى عليكم. '- ' و ان عاقبتم فعاقبوا بمثل ما عوقبتم. 
تعارض منافع: تدوين اين مقاله، فاقد هرگونه تعارض منافعى

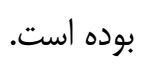

سهم نويسندكان: نغارش و نهايى سازى متن مقاله توسط

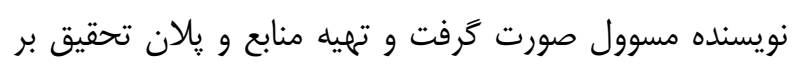

$$
\text { عهده آقاى دكتر شاكرى بوده است. }
$$

تشكر و قدردانى: از تمامى كسانى كه در تهيه اين مقاله ما را رأ

$$
\text { يارى رساندند تشكر مىنماييم. }
$$

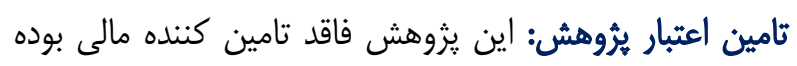
است.
جنايات هستند از ارجحيت برخوردار بوده و مىتوان قصاص در

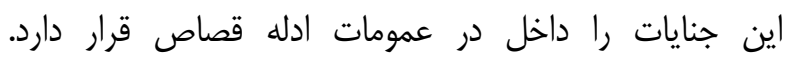
همينطور اقتضاى عدالت و انصاف، جلوگيرى از سوء استفاده و تجرى افراد حكم مىكند كه در صورت بيشرفت علم و

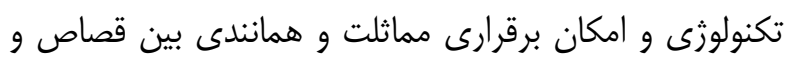

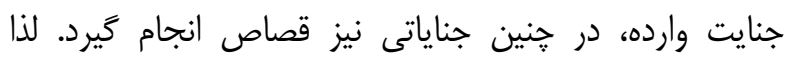

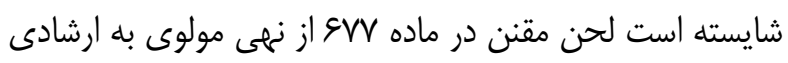
تغيير يافته در تبصرهاى جداگانه فرض قصاص در صورت فوق الذكر تعبيه گَردد. ملاحظات اخلاقى: موارد مربوط به اخلاق در يزوهش و نيز امانتدارى در استناد به متون و ارجاعات مقاله تماماً رعايت كرديد. 
- شاهرودى، سيدمحمود و جمعى از يزوهشگران (عبאا). فرهنَ فقه مطابق مذهب /هل بيت(ع). قم: موسسه

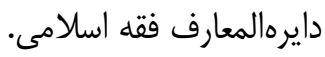

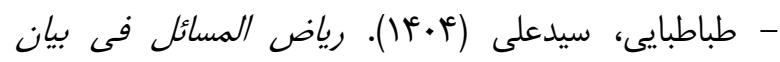
الاحكام بالدلايل. قم: موسسه آل البيت.

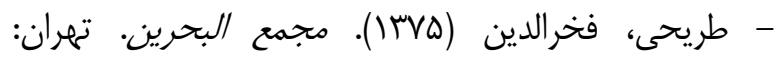

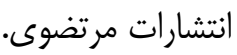
- طوسى، محمد (احسا). المبسوط فى الفقه الاماميه. قم: انتشارات اسلامى.

- طوسى، محمد (V) أ(I). تهذيب الاحكام. جلد ينجم، تهران:

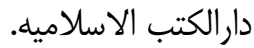
- طوسى، محمد (بى تا). النهايه فى مجرد الفقه و الفتاوى. جلد الداهيه

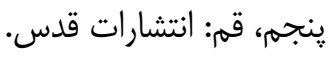
- علامه حلى، حسن بن التشارت فدس. يوسف، (•rأl). تحرير الاحكام الشرعيه على مذهب الاماميه. جلد دوم، قم: موسسه امام

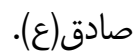
- فراهيدى، خليل بن احمد (•أ(ا). كتاب العين. خاب دوم، قم: نشر هجرت.

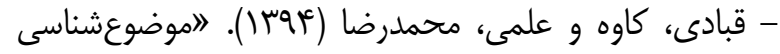

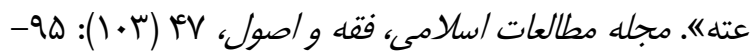

$.11 \mathrm{~V}$

- كاشف النطاء، جعفر (بىتا). كشف النطاء عن مبهمات

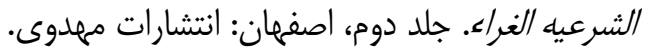

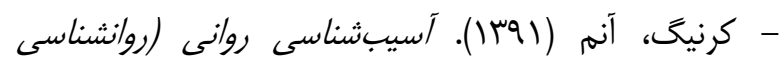

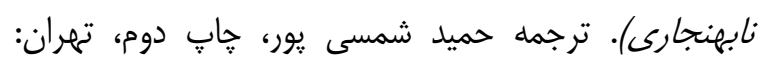

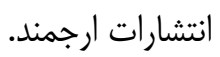

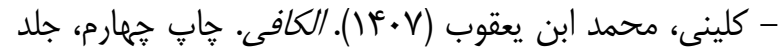
هفدهم، تهران: انتشارات دار الكتب الاسلاميه.

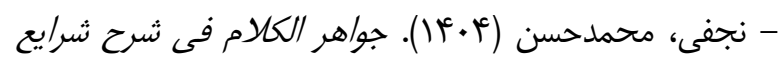

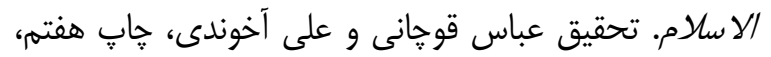
بيروت: داراحياء التراث العربى. - ابنادريس، محمد ابن احمد ( •وسا). السرائر. جلد سوم، قم:

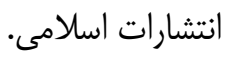
- ابنحمزه، محمد بن على (1+ أبا). الوسيله الى نيل الفضيله.

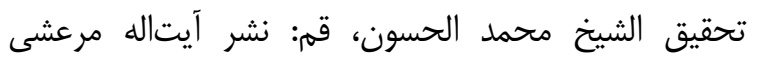
نجفى. - ابنمنظور، محمد بن مكرم (أاعاب). لسان العبب. الطبع الثالث، بيروت: دار الفكر للطباعه و النشر و التوزيع.

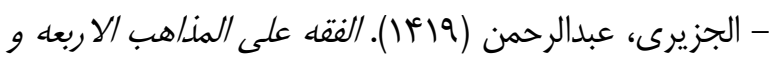
مذهب /هل البيت (ع). بيروت: دارالثقلين.

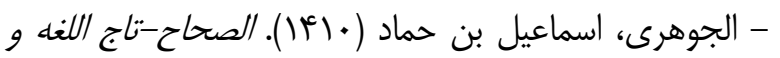
صحاح العربيه. بيروت: دار العلم للملايين.

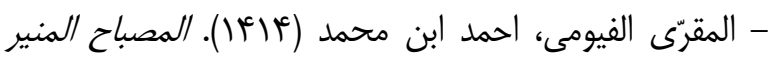
فى غريب الشرح الكبير للرافعى. قم: موسسه دار الهجرها.

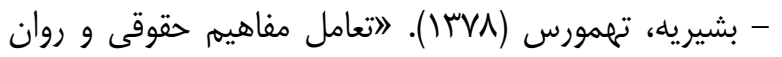
يزشكى جنون"، مجله دانشكده حقوق و علوم سياسى، ئس . $9 \Delta-\wedge \Delta:)^{\mu}(\mu)$ - حر عاملى، محمد بن حسن (1) (1) (I). وسائل الشيعه. قم: موسسه آل البيت (ع). - رضايى، رحمتالله (Vوسا). ديه عقل در حقوق كيفرى

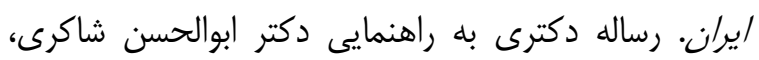
بابلسر: دانشعاه مازندران.

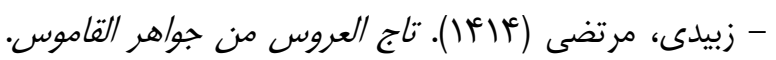
بيروت: دار الفكر للطباعه و النشر.

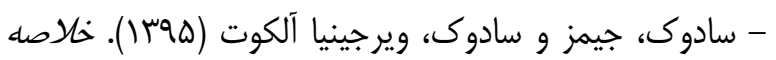
روانيزشكى. ترجمه فرزين رضايى، تهران: انتشارات ارجمند.

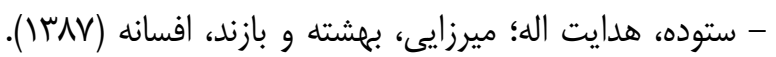

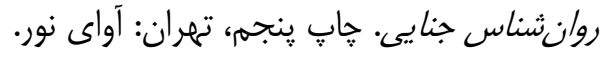

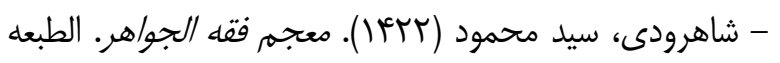
الثانيه، قم: موسسه دايره المعارف الفقه الاسلامى. 


\section{References}

- Ibn Edris, M (1970). Al-Saraer. Vol 3, Qum: Eslami Press. (Arabic)

- Ibn Hamzeh, M (1988). Al-Vasileh. Qum: Marashi Press. (Arabic)

- Ibn Manzour, M (1994). Lesan Al-Arab. $3^{\text {rd }}$ ed. Beirut: Al-Fekr Press. (Arabic)

- Al-Jaziri, A (1999). Al-Feq Ala Mazaheb AlArbae. Beirut: Saqlein Press. (Arabic)

- Al-Johari, E (1990). Al-Sehah. Beirut: Al-Elm Press. (Arabic)

- Al-Moqerri, A (1994). Al-Mesbah Al-Monir. Qum: Al-Hejra Press. (Arabic)

- Bashirieh, T (1999). "Psychological and Legal Definitions of Insanity". Journal of Law and Politics, 38 (3): 85-95. (Persian)

- Hor Ameli, M (1989). Vasel Al- Shia. Qum: Ale Bait Press. (Arabic)

- Rezaei, R (2018). Blood Money of Aql in Iranian Criminal Law. PhD Thesis in Consultation of Abol-Hasan Shakeri, Babolsar: Mazandaran University. (Persian)

- Zobeidi, M (1994). Taj Al-Arous. Beirout: AlFekr Press. (Arabic)

- Sadok, J \& Sadok V (2016). Summary of Psychology. Translated by: Fouzin rezaei, Tehran: Arjmand Press. (Persian)

- Sotoudeh, H (2008). Criminal Psychology. $5^{\text {th }}$ ed. Tehran: Avaye Noor Press. (Persian)

- Shahroudi, SM (2001). Mojam Fiq Javaher. $2^{\text {nd }}$ ed. Qum: Daere Al-Maaref Fiq Press. (Arabic)

- Shahroudi, SM and Others (2005). Farhang Fiq. Qum: Daere Al-Maaref Fiq Press. (Persian)

- Tabatabaei, SA (1984). Riaz Al-Masael. Qum: Ale Bait Press. (Arabic)

- Tarihi, F (1996). Majma Al-Bahrein. Tehran: Mortazavi Press. (Arabic)
- Tousi, M (1987). Tahzib Al- Ahkam. Vol 5, Tehran: Kotob Eslami Press. (Arabic)

- Tousi, M (1971). Al-Mabsout. Qum: Kotob Eslami Press. (Arabic)

- Tousi, M (N.D). Al-Nahaye. Vol 5, Qum: Qods Press. (Arabic)

- Allameh Helli, H (2000). Tahrir Al- Ahkam. Vol 2, Qum: Emam Sadeq Press. (Arabic)

- Farahidi, Kh (1990). Ketab Al-Ein. $2^{\text {nd }}$ ed. Qum: Hejrat Press. (Arabic)

- Qobadi, K \& Elmi, MR (1974). “Atah”. Journal of Islamic Studies, 47 (103): 95-117. (Persian)

- Kashef Al-Qeta, J (N.D). Kashf Al-Qeta. Vol 2, Esfahan: Mahdavi Press. (Arabic)

- Kernic, A (2012). Psychological Pathology. Translated by Hamid Shamsi Pour, $2^{\text {nd }}$ ed. Tehran: Majd Press. (Persian)

- Koleini, M (1987). Al-Kafi. $4^{\text {th }}$ ed. Vol 17, Tehran: Kotob Eslami Press. (Arabic)

- Najafi, M (1984). Javaher Al-Kalam. $7^{\text {th }}$ ed. Beirout: Ehya Toras Arabi Press. (Arabic) 